\title{
HAAS (Christopher), Alexandria in Late Antiquity. Topography and Social Conflict
}

Baltimore-Londres, The Johns Hopkins University Press, 1997, 494 p. (index)S

\section{Christian Décobert}

\section{CpenEdition}

\section{Journals}

Édition électronique

URL : http://journals.openedition.org/assr/20559

DOI : 10.4000/assr.20559

ISSN : $1777-5825$

Éditeur

Éditions de l'EHESS

\section{Édition imprimée}

Date de publication : 1 juillet 2000

Pagination : 80-81

ISBN : 2-222-96691-4

ISSN : 0335-5985

Référence électronique

Christian Décobert, «HAAS (Christopher), Alexandria in Late Antiquity. Topography and Social Conflict», Archives de sciences sociales des religions [En ligne], 110 | avril-juin 2000, document 110-24, mis en ligne le 19 août 2009, consulté le 21 septembre 2020. URL : http://journals.openedition.org/assr/ 20559 ; DOI : https://doi.org/10.4000/assr.20559

Ce document a été généré automatiquement le 21 septembre 2020

(c) Archives de sciences sociales des religions 


\title{
HAAS (Christopher), Alexandria in Late Antiquity. Topography and Social Conflict
}

Baltimore-Londres, The Johns Hopkins University Press, 1997, 494 p. (index)S

\author{
Christian Décobert
}

\section{RÉFÉRENCE}

HAAS (Christopher), Alexandria in Late Antiquity. Topography and Social Conflict, Baltimore-Londres, The Johns Hopkins University Press, 1997, 494 p. (index)

L'objet de cette étude très documentée est de mettre en relation les événements politiques et les phénomènes d'ordre religieux dans l'Alexandrie byzantine. Bien qu'il évoque des faits antérieurs, la tranche chronologique dont traite surtout C.H. se situe entre le début $d u \mathrm{IV}^{\mathrm{e}}$ siècle et le milieu $\mathrm{du} \mathrm{V}^{\mathrm{e}}$, c'est-à-dire la période d'institutionnalisation du christianisme et de la progression exponentielle des conversions à la religion désormais impériale. La thèse de C.H. se résume en peu de mots, et elle est d'ailleurs très explicitement présentée et rappelée dans l'ouvrage : les événements qui durant cette période troublée secouent la capitale égyptienne s'expliquent largement par le factionnalisme religieux. En d'autres termes, les populations de chrétiens et de païens rivalisent pour l'hégémonie culturelle et cultuelle sur la ville, à tel point qu'elles se constituent, dans l'opposition des unes aux autres, en communautés fermées, aux frontières rigides et toujours renouvelées, et subsumant les autres modes de classifications sociales, qu'elles soient économiques, professionnelles ou autres. Dans ce jeu de construction communautaire, les juifs, bien qu'en petit nombre comparés aux chrétiens et aux païens, se donnent un rôle tout à fait semblable à eux et se «reconstituent » en communauté étanche. Au total, la christianisation a 
bouleversé les catégories sociales et a imposé ce que l'on pourrait appeler un ordre communautaire.

L'économie de l'ouvrage suit un plan à la fois chronologique et topographique, montrant bien ainsi que le phénomène "communauta-riste » produisit une véritable topographie nouvelle de la ville. Les chapitres 2 et 3 (The Urban Setting, The Social World) présentent un état de la ville, à la fois social et topographique, avant que la christianisation de l'État ne survienne. Puis (chap. 4, 5, 6: The Jewish Community, The Pagan Community, The Christian Community : The Interior Landscape) on voit l'espace urbain se modifier à mesure

que le christianisme progresse. Des églises à reliques de martyrs se fondent, lesquelles deviennent des pôles d'urbanisation chrétienne ; l'espace public est peu à peu confisqué à l'État: non seulement il se christianise (on y bâtit des églises ou des temples sont transformés en églises) mais aussi il se privatise (certains nouveaux sanctuaires sont les fondations de familles de notables converties).

4 Mais ce phénomène de factionnalisme ne se situe pas seulement au niveau de l'antagonisme entre païens et chrétiens. Très vite, c'est à l'intérieur même de la masse chrétienne qu'il se déploie (chap. 7 et 8 : The Inner Life of the Christian Community: Clergy and People, Community and Factionalism in the Christian Community). Les virtuoses chrétiens du religieux se partagent désormais entre fonctions épiscopales et fonctions monastiques, chacune s'insérant à l'intérieur et à l'extérieur de la ville selon un certain mode : les moines fabriquant du désert urbain, l'évêque (le patriarche) et son entourage recréant une centralité métropolitaine sur un tissu d'églises épiscopales. Quant aux formations schismatiques, l'arianisme essentiellement, elles ne sont pas hors du jeu : elles se constituent elles aussi en quartiers...

5 Ce mode de compréhension des mouvements sociaux liés à la christianisation de l'empire n'a pas la prétention de tout expliquer. Mais il peut embrasser large, et il peut en tout cas montrer comment l'espace urbain n'est pas seulement la scène où se produisent les mutations religieuses, mais qu'il en est aussi, et peut-être prioritairement, l'enjeu. De ce point de vue, nombre de faits supposés bien connus de l'histoire alexandrine sont reconsidérés par l'auteur, ainsi les relations difficiles entre Athanase et l'empereur Julien et la stratégie urbaine d'Athanase, le meurtre d'Hypatie dans le Césareum et la possible implication de l'évêque Cyrille, ou encore le recrutement social de l'arianisme. Certes, ces reconsidérations ont le don d'irriter quelques collègues spécialistes qui ne manquent pas (n'ont pas manqué) de signaler telle approximation topographique, telle insuffisance bibliographique, telle incompréhension linguistique. L'exercice de relecture historique est difficile, il est parfois risqué et l'on saura gré à C.H. de s'y être lancé.

On regrettera cependant l'absence étrange de bibliographie : il aurait été bien utile au lecteur non seulement de saisir l'ampleur des sources utilisées par l'A. mais aussi de situer d'emblée ses lectures méthodologiques. 